\title{
El Libro de Manuel
}

Libro de Manuel, la novela de Cortázar de reciente aparición, ${ }^{1}$ apunta a cierto cambio en la temática del escritor. El cambio está bien resumido por Cortázar: es "el paso del yo al tá o al vos. Y del vos a todo el resto. Es, en el plano literario, mi evolución en el plano personal" ( $A B C$ de las Américas, No. 34, 2-8 junio 1973, p. 53).

Hay algunos efectos gráficos que están bien integrados en la novela, y to son excesivos. Aparecen en su mayoría como noticias de periódicos que el lector va leyendo al mismo tiempo que los protagonistas. También al principio, cuando Cortázar presenta a los personajes, lo hace colocando los nombres en una lista vertical a la izquierda de la página con el texto a la derecha. La escena está presentada como un escenario y los personajes como espectadores de una función. Pero no pueden asistir al espectáculo pues en vez de escenario hay sólo una pared de ladrillos. La lista de nombres, entonces, representaría las plateas en donde los personajes están sentados y el texto la pared. El esfuerzo de imaginación que deben hacer los personajes para traspasar la pared y lograr que la acción comience es el mismo esfuerzo que debe hacer el lector. Una vez derribado ese obstáculo, la novela empieza a desarrollarse sin impedimentos físicos.

Nuevamente Cortázar nos coloca frente a un grupo cosmopolita. Las conversaciones tratan temas como el peronismo (ver especialmente pp. 261-262), la función y el compromiso del escritor (p. 234), entre otros. De este grupo de personajes se destaca "el que te dije", personaje-escritor, complementado en este sentido por Andrés y Marcos. Andrés, personaje que intuimos como uno de los más importantes, entre otros motivos por el uso de la primera persona empleado casi exclusivamente en su caso, es un argentino en Paris, donde transcurre la acción. Tiene un sueño en el que está la clave de su destino ( $\mathrm{y}$ de la novela también, a la vez que del autor). El momento decisivo en el sueño está marcado

1 (Buenos Aires: Editorial Sudamericana, 1973). 
por un corte en una escena que es "un perfecto montaje de cine" (102). En este corte ocurre algo que Andrés debe descubrir pero que por el momento aparece como una mancha negra. Mucho más adelante en la novela, durante su viaje iniciático, Andrés finalmente vislumbra lo que ocurrió en ese corte, dentro del cuarto a oscuras que por fin se ilumina. La palabra clave que se pronuncia en esa escena es el momento de revelación que marca el destino de Andrés. Además, ante la encrucijada fisica que se le presenta, Andrés se ve en la necesidad de elegir la ruta. Hay dos calles; una va a la izquierda, la otra a la derecha. Andrés decide: "por supuesto izquierda dado que la naturaleza imita al arte" (351). De esta manera termina la indecisión a la vez que la pasividad. Asi como Andrés debe tomar este único camino posible, el de la acción, asi también lo ha decidido Cortázar; Andrés con su participación, Cortázar escribiendo esta novela ( $\mathrm{y}$ al mismo tiempo cediendo los derechos a los presos políticos, cosa que ya adelantaba en parte en el prólogo).

El objetivo de los personajes de la novela es la preparación de la Joda. La Joda es una operación complicada, llevada a cabo paso a paso con gran precisión y perfecto planeamiento, que tiene como objeto el secuestro del Vip para obtener en cambio la libertad de varios prisioneros políticos. Así como asistimos en detalle a su realización y punto culminante, una vez llevada a cabo Cortázar no nos dice mucho acerca del desenlace. En Rayuela, Cortázar se rebeló contra la novela que es un "rollo chino". Estructuralmente, Libro de Manurel comienza en el primer capítulo (sin numerar) por el final de la aventura y de ahí en adelante se vuelve atrás, al desarrollo de los preparativos y la ejecución, día a dia, hora por hora, sistemáticamente. El capítulo final es uno de los mejores, elevándose a un tono lírico y a la vez patético. Al comienzo de la novela hay esbozos de temas recurrentes como el de las figuras, y también reaparece la imagen del puente, favorita de Cortázar. Toda Ia novela es el recuento de un gran juego: la Joda. Como todo juego basado en el ritual exige víctimas y sacrificios.

El libro de Manuel, que da título a la novela, es una colección de recortes de diarios en el que todos contribuyen, y que servirá para la educación del hijo de Susana y Patricio; es para Manuel y a través de él, "por tanto Manuel en tanto rincón del mundo, queriendo ayudarlo a que algún día entrara en un ciclo diferente y a la vez salvándole algunos restos del naufragio total" (183). El nombre del niño es obviamente significativo (recordemos también que la clocbarde en Rayzela se llama Emmanuèle). Las noticias de los periódicos son, en su mayoría, 
sobre actos de violencia y torturas de prisioneros políticos. Hacia el final hay una gran acumulación de noticias y testimonios de torturas (PP. 370-381). Pero no será todo trágico para las lecturas de Manuel, pues Andrés se ha encargado de agregar dibujos divertidos y noticias poco serias en un descuido de Susana. El libro será más equilibrado. La no. vela también sigue el mismo criterio propuesto por Andrés para el libro del niño. En los preparativos de la Joda abunda el humor. Las escenas de los alaridos en el cine, las comidas de pie en restaurantes elegantes, los saludos y agradecimientos efusivos al desconcertado conductor del ómnibus, el paseo del pingüino turquesa, son escenas de efectiva comicidad que Cortázar maneja con indiscutible excelencia. Además, en esta novela el lenguaje es directo, preciso y a la vez hermoso. Los pasajes eróticos son excelentes y pocas veces tan logrados en la literatura hispanoamericana hasta ahora.

Altemando entre la tortura y la risa, el amor y la muerte, el suspenso y la acción, Cortázar sobresale como escritor en Libro die Manuel, testimonio de una época y de la posición ideológica que su autor quiso expresar. Pero más allá de posiciones ideológicas y su manifestación, creemos que el mayor mérito literario de la novela se manifiesta en especial a través de dos vías en las que Cortázar descuella: la comicidad y el erotismo.

Martha paley de Francescato

Unitversity of Illinois 
